\title{
COMPARATIVE STUDY REGARDING THE LEVEL OF ANXIETY IN VARIOUS CATEGORIES OF ATHLETES
}

\author{
Catalina Ababei \\ * "Vasile Alecsandri” University of Bacau, 157, Calea Mărăşeşti Street, Bacau, 600115, Romania, \\ e-mail: ababeicatalina@ub.ro
}

\begin{abstract}
The Romanian Language Dictionary (2009) defines anxiety as inquietude, unrest, fear. The athletes' emotional states can change easily, especially in less experienced athletes, often near a competition that demands reaching a goal, or when they find themselves in new situations. This can cause them to block or have no reaction in key moments. Professional sports regard anxiety as a normal reaction of the athlete's body, believing that in this manner it adapts to new conditions and functional parameters. The study was based on the hypothesis stating that anxiety could have various levels in athletes before a competition, according to their sport. The research was conducted on 45 athletes practicing wrestling, track and field, and boxing at a national level, for various Bacau sports clubs. The main research method for this study was the inquiry, and the working instrument was the questionnaire -J. Taylor's anxiety scale.
\end{abstract}

Keywords: anxiety, athlete, categories

\section{Introduction}

Considering that this study is about athletes whose main goal is to record top performances, the author believes that the notion of "top performance" must be first defined. Predoiu (2016) makes a summary of all definitions and concludes that top performance represents the peak of what an individual or a group can possibly achieve, according to their skills and the social and environmental factors. Among the summarized definitions, there is one that names top performance "a bio-psycho-social value achieved within an official competition, as a result of an ability that is multiply determined and assessed on the basis of rigorous criteria or standards" (Dragnea, Mate-Teodorescu, cited in Predoiu, 2016, 11); or it is simply called a "record" (Epuran, Holdevici, Tonița, 2008). But regardless of how much or how little a definition of top performance might be, it could not include or be summarized in a simple formula that once applied could guarantee any success. That is because the factors contributing to the success in sports depend, in their turn, on a series of variables that cannot be anticipated and measured. Among these factors one can count anxiety, which the author wishes to focus on in this paper. Anxiety is a natural part of performance, either in the court, or in the pool. Even the great athletes get nervous before a competition (Ababei, R., 2006). The Encyclopedia of Psychology (Kazdim, 2000) defines anxiety as an emotion comprising worry, its effects being increased blood pressure, fainting sensation (Robu, 2011).

A person with a high level of anxiety feels under constant threat, being in a permanent state of nervousness (Holdevici $(2002,13)$. Of course, this negatively influences both the training process and especially the athlete's performance during a competition. Nevertheless, not all studies prove that anxiety is completely negative. Thus, Hofseth (2016) mentions that certain studies by Jones, Hanton, Swein, of 1995 and by Perry, Williams of 1998, prove that the athletes with top performances view anxiety symptoms as stimulating or as positive emotions. However, studies by Beilock and Gray (cited in Hofseth, 2016) have shown that a high level of anxiety can have a negative effect also in highly trained athletes, especially during the maximum pressure/tension moments of the competition, when they have to accomplish a motor task. 


\section{Purpose, hypothesis, and research methods}

The purpose of this research was to test the junior athletes practicing track and field, wrestling, and boxing in Bacau. The athletes who have accepted to take part in the study have results that put them in the top ten at a national level. The study was based on the hypothesis stating that anxiety could have various levels in athletes before a competition, according to their sport.

This study used the documentation method, the inquiry method (the questionnaire being the main working instrument), the statistical-mathematical method for interpreting the data, and the graphical representation method.

\section{Research subjects}

The research was conducted on 45 athletes who voluntarily agreed to fill out the Manifest Anxiety Scale created by J. Taylor. The subjects were 12 females and 33 males, aged between 16 and 18 years old. Initially there were 48 questionnaires distributed, but 45 were validated, 15 for each of the sport mentioned above.

\section{Development of the research}

The research was conducted between April and May, 2019. The questionnaires were distributed seven days before the competitions, according to the sport of the subjects. What follows is the applied questionnaire, aimed to measure the anxiety level. It has 50 items, to which the subjects had to answer by Yes or No, based on their own feelings.

The testing was done individually, taking in average 20-25 minutes. The items were as follows:

1. I am usually calm and not easily upset.

2. I believe I am no more nervous than most others.

3. I usually sleep well.

4. I have very few headaches.

5. I do not tire quickly.

6. I am happy most of the time.

7. I am entirely self-confident.

8. I practically never blush.

9. I have very few fears compared to my friends.

10. I am usually in a good mood.

11. I hardly ever notice my heart pounding and I am seldom short of breath.

12. My hands are usually warm.

13. I blush no more often than others.

14. I am certainly lacking in self-confidence.

15. At times I think I am no good at all.

16. I have periods of such great restlessness that I cannot sit long in a chair.

17. I find it difficult to fall asleep at night.

18. I shrink from facing a crisis of difficulty.

19. I wish I could be as happy as others seem to be.

20. I have sometimes felt that difficulties were piling up so high that I could not overcome them.

21. I dream frequently.

22. I frequently notice my hand shakes when I try to do something.

23. My sleep is fitful and disturbed.

24. I worry quite a bit over possible misfortunes.

25. I have been afraid of things or people that I know could not hurt me.

26. I find it hard to keep my mind on a task or job. 
27. I work under a great deal of tension.

28. I find myself getting into trouble easily.

29. I feel anxiety about something or someone almost all the time.

30. I am inclined to take things hard.

31 . I cry easily.

32. I am troubled by attacks of nausea.

33. I am very nervous about my health.

34. I am often afraid that I am going to blush.

35. I worry about being around people.

36. I worry over money and business.

37. I am sometimes thinking about things that are best kept to myself.

38. I have had periods in which I lost sleep over worry.

39. Sometimes when embarrassed, I break out in a sweat.

40. I sweat very easily even on cool days.

41. Sometimes I become so excited that I find it hard to get to sleep.

42. I am an irritable person.

43. I certainly feel useless at times.

44. Sometimes I feel that I'm having a nervous breakdown and I'm going to lose my temper.

45. I frequently find myself worrying about something.

46. I am more sensitive than most other people.

47. I feel hungry almost all the time.

48. I do not like sudden changes.

49. Life is a trial for me much of the time.

50. It makes me nervous to have to wait.

\section{Results of the research}

The results were analyzed according to the methodology accompanying the scale. Thus, the author calculated the Yes answers for items 14-50 (a) and the No answers for items 1-13 (b). At the end, the author calculated the sum of (a) and (b).

According to J. Taylor, the results are classified as follows:

- 40-50 points indicate a very high level of anxiety;

- 25-40 points indicate a high level of anxiety;

- 15-25 points indicate a medium (to high) level of anxiety;

- 5-15 points indicate a medium (to low) level of anxiety;

- 0-5 points indicate a low level of anxiety.

Table 1 presents the data recorded by the track and field athletes.

Table 1 Data regarding the level of anxiety in track and field athletes

\begin{tabular}{|c|c|c|c|c|}
\hline $\begin{array}{c}\text { No. } \\
\text { Subject }\end{array}$ & Age & $\begin{array}{c}\text { Gender } \\
\mathbf{M} / \mathbf{F}\end{array}$ & Score & Anxiety level \\
\hline 1 & 16 & M & 11 & \multirow{5}{*}{ Medium (to low) level of anxiety } \\
\hline 2 & 16 & $\mathrm{~F}$ & 11 & \\
\hline 3 & 16 & $\mathrm{~F}$ & 10 & \\
\hline 4 & 17 & $\mathrm{~F}$ & 14 & \\
\hline 5 & 18 & $\mathrm{~F}$ & 12 & \\
\hline 6 & 16 & $\mathrm{~F}$ & 23 & \multirow{5}{*}{ Medium (to high) level of anxiety } \\
\hline 7 & 18 & $\mathrm{~F}$ & 22 & \\
\hline 8 & 18 & $\mathrm{~F}$ & 17 & \\
\hline 9 & 16 & $\mathrm{~F}$ & 16 & \\
\hline 10 & 18 & $\mathrm{M}$ & 16 & \\
\hline
\end{tabular}




\begin{tabular}{|l|l|l|l|l|}
\hline 11 & 16 & F & 19 & \\
\hline 12 & 16 & F & 15 & \\
\hline 13 & 16 & F & 27 & \multirow{2}{*}{ High level of anxiety } \\
\hline 14 & 16 & F & 26 & \\
\hline 15 & 18 & F & 26 & \\
\hline
\end{tabular}

As one can see in table 1 , none of the track and field athletes $(0 \%)$ has recorded a low level of anxiety and none $(0 \%)$, a very high level of anxiety. Out of these athletes, $33 \%$ recorded a medium (to low) level of anxiety, while most of them (46.66\%) recorded a medium (to high) level of anxiety before competition.

Graphically, the results are expressed as follows (Figure 1):

Figure 1 Distribution on anxiety of the track and field athletes

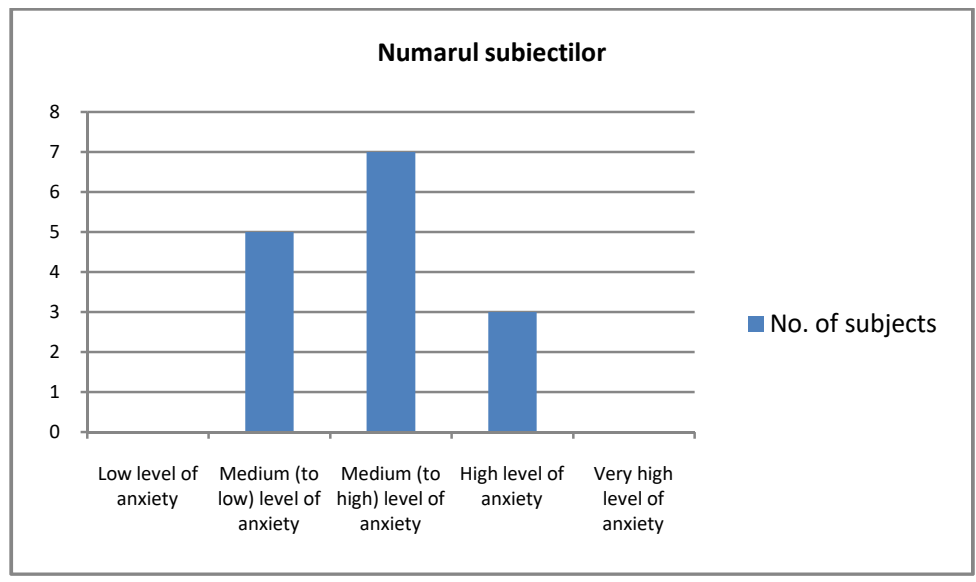

Table 2 Data regarding the level of anxiety in wrestlers

\begin{tabular}{|c|c|c|c|c|}
\hline $\begin{array}{c}\text { No. } \\
\text { Subject }\end{array}$ & Age & $\begin{array}{c}\text { Gender } \\
\mathbf{M} / \mathbf{F}\end{array}$ & Score & Anxiety level \\
\hline 1 & 17 & $\mathrm{M}$ & 10 & \multirow{4}{*}{ Medium (to low) level of anxiety } \\
\hline 2 & 17 & $\mathrm{M}$ & 9 & \\
\hline 3 & 16 & $\mathrm{M}$ & 12 & \\
\hline 4 & 16 & $\mathrm{M}$ & 10 & \\
\hline 5 & 16 & $\mathrm{M}$ & 22 & \multirow{10}{*}{ Medium (to high) level of anxiety } \\
\hline 6 & 17 & M & 17 & \\
\hline 7 & 16 & $\mathrm{M}$ & 18 & \\
\hline 8 & 16 & $\mathrm{M}$ & 17 & \\
\hline 9 & 16 & $\mathrm{M}$ & 24 & \\
\hline 10 & 17 & $\mathrm{M}$ & 16 & \\
\hline 11 & 16 & $\mathrm{M}$ & 21 & \\
\hline 12 & 18 & $\mathrm{M}$ & 18 & \\
\hline 13 & 16 & $\mathrm{M}$ & 18 & \\
\hline 14 & 17 & $\mathrm{M}$ & 18 & \\
\hline 15 & 15 & $\mathrm{M}$ & 26 & High level of anxiety \\
\hline
\end{tabular}

The table above shows that the wrestlers also did not record a low or a very high level of anxiety. In other words, there are no anxiety extremes in the wrestlers. Four athletes $(26.66 \%)$ recorded a medium (to low) level of anxiety, ten subjects (66.66\%), a medium (to high) level of anxiety, and only one subject (6.66\%) recorded a high level of anxiety.

Graphically, the results are expressed as follows (Figure 2): 
Figure 2 Distribution on anxiety of the wrestlers

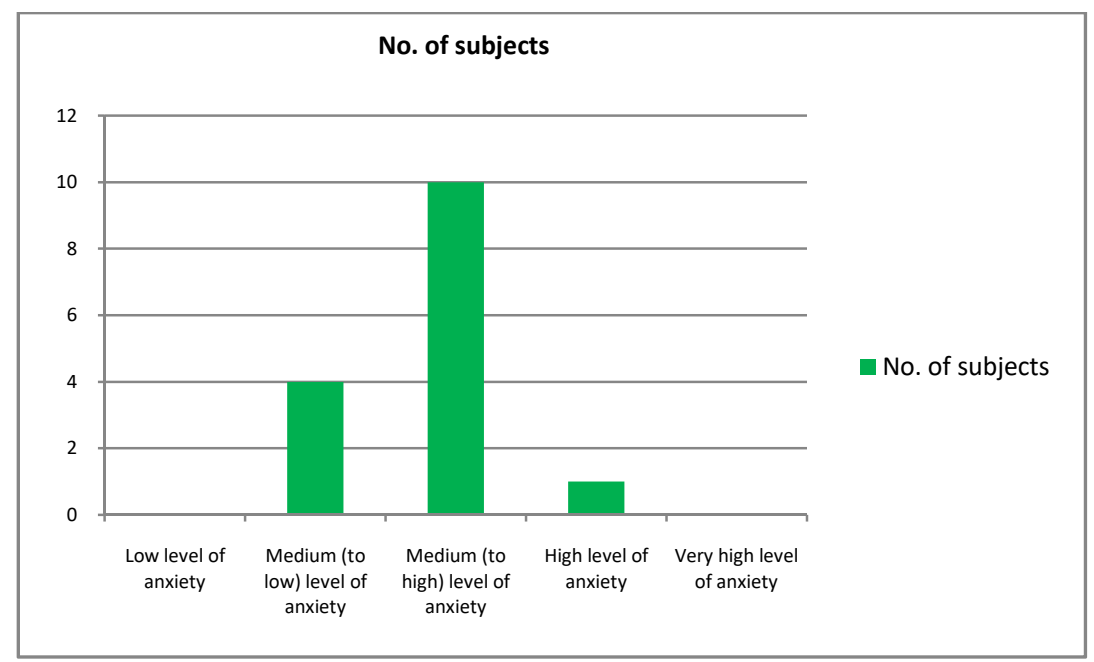

Table 3 presents the data recorded by the boxers.

Table 3 Data regarding the level of anxiety in boxers

\begin{tabular}{|c|c|c|c|c|}
\hline $\begin{array}{c}\text { No. } \\
\text { Subject }\end{array}$ & Age & $\begin{array}{c}\text { Gender } \\
\mathbf{M} / \mathbf{F}\end{array}$ & Score & Anxiety level \\
\hline 1 & 16 & $\mathrm{M}$ & 5 & Low level of anxiety \\
\hline 2 & 18 & $\mathrm{M}$ & 10 & \multirow{2}{*}{ Medium (to low) level of anxiety } \\
\hline 3 & 16 & $\mathrm{M}$ & 12 & \\
\hline 4 & 18 & $\mathrm{M}$ & 18 & \multirow{2}{*}{ Medium (to high) level of anxiety } \\
\hline 5 & 16 & $\mathrm{M}$ & 19 & \\
\hline 6 & 16 & $\mathrm{M}$ & 20 & \\
\hline 7 & 18 & $\mathrm{M}$ & 18 & \\
\hline 8 & 18 & $\mathrm{M}$ & 17 & \\
\hline 9 & 17 & $\mathrm{M}$ & 17 & \\
\hline 10 & 15 & $\mathrm{M}$ & 15 & \\
\hline 11 & 17 & $\mathrm{M}$ & 20 & \multirow{2}{*}{ High level of anxiety } \\
\hline 12 & 16 & $\mathrm{M}$ & 20 & \\
\hline 13 & 17 & $\mathrm{M}$ & 25 & \multicolumn{1}{|}{} \\
\hline 14 & 17 & $\mathrm{M}$ & 34 & \\
\hline 15 & 17 & $\mathrm{M}$ & 31 & \\
\hline
\end{tabular}

Unlike in the track and field athletes and the wrestlers, one boxer (6.66\%) recorded a low level of anxiety. It must be mentioned also that none of the athletes, no matter the sport, did not record a very high level of anxiety. In this case also, most subjects $(60 \%$ - nine of them) recorded a medium (to high) level of anxiety. $13.33 \%$ of them recorded a medium (to low) level, and $20 \%$, a high level of anxiety. Graphically, the results are expressed as follows (Figure 3): 
Figure 2 Distribution on anxiety of the boxers

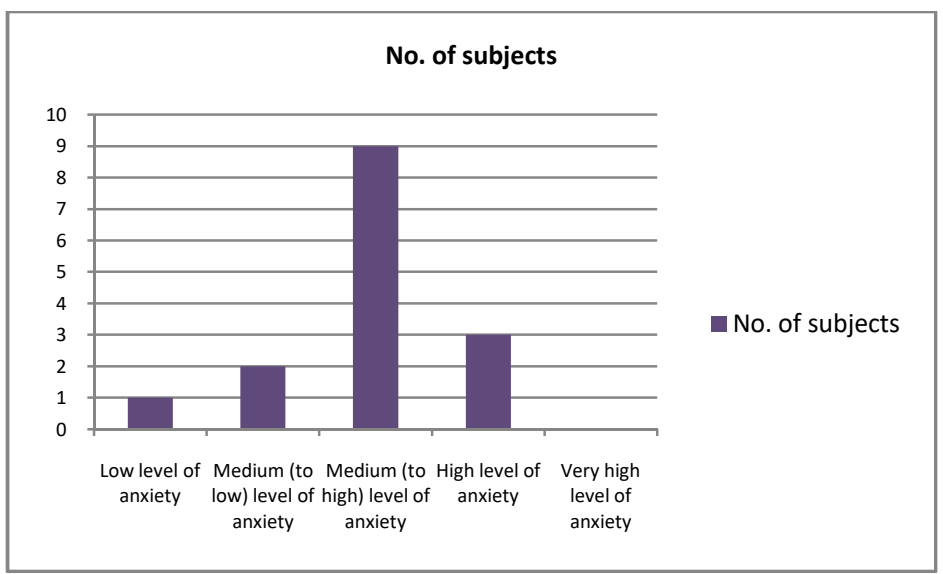

\section{Conclusions}

This study has partially confirmed the initial hypothesis, in the sense that before a competition there are different values between the track and field athletes, wrestlers, and boxers, in regard to their level of anxiety, but they are not significant. However, one can notice that regardless of the sport, the highest percentage was for the medium to high level of anxiety, recorded by $60 \%$ of the boxers, $66.66 \%$ of the wrestlers, and $46.66 \%$ of the track and field athletes. In regard to the medium to low level, it was recorded by $33.33 \%$ of the track and field athletes, $26.66 \%$ of the wrestlers, and $13.33 \%$ of the boxers. To summarize, a medium (to low and high) level of anxiety was recorded by $93.2 \%$ of the wrestlers, $80 \%$ of the track and field athletes, and $73.3 \%$ of the boxers. In conclusion, it can be said that all athletes get nervous, but the way in which they can manage their emotions can lead them to better or weaker results in relation to their personal records.

\section{References}

1. Ababei, R.,(2006) Teoria și Metodologia Antrenamentului Sportiv [Theory and methodology of sports training], Pim

2. Bailey, M., (2014) Mind games: how footballers use sports psychology, The Telegraph. Retrieved 1 June 2018, https://www.telegraph.co.uk/men/active/10568730/Mind-gameshow-footballers-use-sports-psychology.html

3. Dicţionarul Explicativ al Limbii Române (2009). Bucharest: Univers Enciclopedic Gold

4. Epuran, M., Holdevici, I., \&Toniţa, F. (2008) Psihologia sportului de performanţă: teorie şi practică [Psychology of professional sports: theory and practice] Fest

5. Hofseth, E. (2016) Stress, emotions, and coping in elite football players: a study of negative emotions, defensive self-presentation strategies, and their relationships to skill and performance level

6. Kazdin, A. E. (2000). Encyclopedia of psychology. Oxford University Press

7. Predoiu, R. (2016) Psihologia Sportului. Maximizarea performanței sportive [Sports psychology. Maximizing top athletic performance], Polirom

8. Robu, V. (2011) Psihologia Anxietăţii faţă de Testări și Examene [Psychology of anxiety in relation to tests and examinations]. Performantica

9. Taylor, S. E., \& Stanton, A. L. (2007) Coping resources, coping processes, and mental health. Annu. Rev. Clin. Psychol., 3, 377-401 